Journal of Telenursing (JOTING)

Volume 3, Nomor 1, Juni 2021

e-ISSN: 2684-8988

p-ISSN: 2684-8996

DOI: https://doi.org/10.31539/joting.v3i1.2079

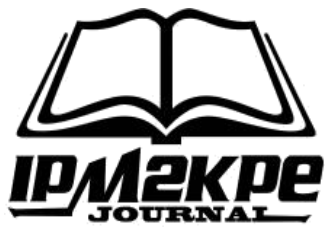

\title{
TERAPI PSIKOEDUKASI TERHADAP SELF CARE ACTIVITY PADA PENDERITA DIABETES MELLITUS
}

\author{
Argi Virgona Bangun ${ }^{1}$, Fitria Ningsih ${ }^{2}$ \\ STIKES Jenderal Achmad Yani Cimahi ${ }^{1}$ \\ Rumah Sakit Kharisma Subang ${ }^{2}$ \\ argie.virgona@gmail.com ${ }^{1}$
}

\begin{abstract}
ABSTRAK
Penelitian ini bertujuan untuk mengetahui perbedaan rerata sebelum dan sesudah pelaksanaan terapi psikoedukasi terhadap self-care activity pada penderita diabetes mellitus di RW 07 wilayah kerja Puskesmas Cimahi Tengah. Metode dalam penelitian ini menggunakan pre-eksperimen, dengan desain penelitian one grup pretest-posttest. Sampel dalam penelitian ini adalah penderita diabetes millitus tipe 2. Penelitian ini menggunakan consecutive sampling sebanyak 11 responden. Terapi psikoedukasi diberikan selama 5 kali pertemuan dalam 21 hari dan pengukuran self-care activity menggunakan kuesioner SDSCA, lalu data diolah dengan menggunakan analisa univariat (mean, SD, 95\% CI, dan Min-Max) dan bivariat (uji t-dependen). Hasil pretest diperoleh 10,63 dan postest-nya adalah 23,00 serta Pvalue 0.001. Simpulan, terdapat pengaruh terapi psikoedukasi terhadap self-care activity pada penderita diabetes mellitus.
\end{abstract}

Kata Kunci: Diabetes Millitus, Psikoedukasi, Self-Care Activity

\begin{abstract}
This study aims to determine the difference in the mean before and after the implementation of psychoeducation therapy on self-care activities in diabetes mellitus sufferers in RW 07 in the work area of Puskesmas Cimahi Tengah. The method in this study used a pre-experiment, with a one group pretest-posttest research design. The sample in this study were patients with type 2 diabetes millitus. This study used a consecutive sampling of 11 respondents. Psychoeducation therapy was given for 5 meetings in 21 days and measurement of self-care activity using the SDSCA questionnaire, then the data were processed using univariate analysis (mean, SD, 95\% $C I$, and Min-Max) and bivariate (t-dependent test). The pretest results obtained were 10.63 and the posttest was 23.00 and the Pvalue was 0.001. In conclusion, there is an effect of psychoeducation therapy on self-care activity in diabetes mellitus sufferers.
\end{abstract}

Keywords: Diabetes Millitus, Psychoeducation, Self-Care Activity 


\section{PENDAHULUAN}

Organisasi International Diabetes Federation (IDF) memperkirakan sedikitnya terdapat 463 juta orang pada usia 20-69 tahun di dunia menderita diabetes pada tahun 2019 dan angka tersebut diprediksi terus meningkat hingga mencapai 578 juta di tahun 2030. Saat ini Indonesia menempati urutan ke-7 negara dengan jumlah penderita diabetes tertinggi, yaitu sejumlah 10,7 juta pada tahun 2019 (IDF Diabetes Atlas, 2019). Prevalensi Diabetes Millitus (DM) nasional adalah sebesar 8,5\% atau sekitar 20,4 juta orang Indonesia terkena DM. Sementara itu, jika dibandingkan dengan tahun 2013, prevalensi DM berdasarkan diagnosis dokter pada penduduk umur $\geq 15$ tahun di provinsi Jawa Barat meningkat menjadi 1,7 \% (Kemenkes RI, 2018).

Dalam upaya menurunkan prevalensi DM yang semakin meningkat di masa depan peran dari berbagai pihak yang terkait sangatlah penting. Salah satunya adalah perawat, dimana perannya sebagai health educator bertanggung jawab memberikan edukasi dan konseling untuk meningkatkan pemahaman penyandang DM. Hasil penelitian Massi \& Kallo (2018) menunjukan metode edukasi dengan video dan FGD sangat efektif digunakan untuk meningkatkan pengetahuan pasien DM. Sementara itu, penelitian lain yang dilakukan Huzaimah (2018) menunjukan bahwa modifikasi psikoedukasi dapat meningkatkan pemahaman dan efikasi diri penyandang DM.

Tujuan penatalaksanaan DM secara umum adalah meningkatkan kualitas hidup penyandang DM, dimana target akhirnya yaitu turunnya morbiditas dan mortalitas DM (PERKENI, 2019). Hal ini dapat terwujud jika penyandang DM memiliki self-care activity yang baik, karena DM merupakan penyakit yang akan diderita seumur hidup. Penelitian yang dilakukan Hidayah (2019) menunjukan bahwa perilaku selfmanagement diabetes dapat mempengaruhi kadar gula darah. Oleh karena itu diperlukan pemahaman yang baik mengenai pengelolaan dan pengendalian DM sehingga dapat menekan kejadian komplikasi DM. Diabetic self-care activities terdiri dari diet, aktivitas fisik, pemeriksaan gula darah, perawatan kaki, pengobatan, serta aktivitas merokok dapat digunakan sebagai rujukan keberhasilan terapi DM (Sugiharto et al., 2019).

Data awal yang diperoleh melalui tehnik wawancara, diketahui bahwa 6 dari 7 penyandang DM sudah didiagnosa lebih dari 5 tahun. Dilihat dari beberapa aspek selfcare activitiy, hampir semua mengatakan tidak pernah lalai meminum obat maupun menyuntik insulin. Namun demikian hanya 2 orang yang mengaku menjalankan diet DM. Di samping itu, pendidikan kesehatan rutin dilaksanakan 1 bulan sekali di puskesmas dalam bentuk ceramah. Terapi psikoedukasi dalam penelitian ini dilakukan dengan metode diskusi kelompok terarah, dengan tujuan untuk menyamakan persepsi responden mengenai penatalaksanaan DM serta memancing responden aktif dalam berdiskusi. Hal ini menjadi aspek yang signifikan, karena seluruh responden termasuk kelompok lansia dengan latar tingkat pendidikan rendah. Berdasarkan fenomena tersebut, maka perlu dilakukan penelitian tentang efektivitas terapi psikoedukasi terhadap self-care activity pada penyandang DM. 


\section{METODE PENELITIAN}

Penelitian ini peneliti menggunakan jenis penelitian pre-eksperimen dengan pendekatan one grup pretest-posttest. Jenis sampel dalam penelitian ini adalah nonprobability sampling dan menggunakan tehnik consecutive sampling dengan jumlah sampel 11 orang penyandang DM. Instrumen yang digunakan adalah booklet psikoedukasi dan kuesioner The Summary of Diabetes Self-Care Activities (SDSCA). Analisis data dilakukan secara univariat dan bivariat menggunakan uji t dependent.

\section{HASIL PENELITIAN}

Tabel. 1

Rerata Self-Care Activity pada Penyandang DM Sebelum Terapi Psikoedukasi

\begin{tabular}{ccccc}
\hline Variabel & $\mathrm{N}$ & Mean & SD & Min-Max \\
\hline Pretest self-care activity & 11 & 10,63 & 2,34 & $5,5-13,5$ \\
\hline
\end{tabular}

Tabel 1 menunjukan bahwa dari 11 responden diperoleh nilai rerata self-care activity sebelum dilakukan intervensi terapi psikoedukasi 10,63.

Tabel. 2

Rerata Self-Care Activity pada Penyandang DM Setelah Terapi Psikoedukasi

\begin{tabular}{ccccc}
\hline Variabel & N & Mean & SD & Min-Max \\
\hline Posttest self-care activity & 11 & 23,00 & 4,73 & $12,0-28,0$ \\
\hline
\end{tabular}

Tabel 2 menunjukan bahwa dari 11 responden diperoleh nilai rerata self-care activity 23,00.

Tabel. 3

Perubahan Self-Care Activity pada Penyandang DM

Sebelum dan Setelah Terapi Psikoedukasi

\begin{tabular}{ccccc}
\hline Variabel & N & Mean & SD & Pvalue \\
\hline Pretest self-care activity & 11 & 10,63 & 2,34 & 0,001 \\
\hline Posttest self-care activity & 11 & 23,00 & 4,73 & 0,001 \\
\hline
\end{tabular}

Berdasarkan tabel 3, nilai rerata self-care activity meningkat sesudah dilakukan terapi psikoedukasi. Analisis lebih lanjut menunjukan adanya perbedaan yang bermakna/ signifikan rata-rata self-care activity penyandang DM sebelum dan setelah pemberian terapi psikoedukasi ( $\left.\mathrm{P}_{\text {value }} 0.001\right)$.

\section{PEMBAHASAN}

\section{Self-Care Activity Sebelum Terapi Psikoedukasi}

Hasil penelitian yang terdapat pada tabel 1 menunjukan bahwa nilai rerata selfcare activity sebelum dilakukan terapi psikoedukasi adalah 10,63 yang bermakna bahwa responden memiliki self-care activity yang buruk. The Summary of Diabetes Self-Care Activities (SDSCA) adalah kuesioner lapor diri yang digunakan untuk mengukur frekuensi self-care activity responden dalam waktu 7 hari berturut-turut. Aspek yang dinilai adalah diet, aktivitas fisik, pemeriksaan gula darah, perawatan kaki, pengobatan, 
serta aktivitas merokok (Sugiharto et al., 2019). Dalam hal ini responden diketahui sulit sekali untuk menjalankan diet, melakukan olahraga rutin serta masih tidak dapat meninggalkan kebiasaan merokok. Temuan saat pengambilan data, sebagian besar responden kerap mengkonsumsi minuman kemasan serta jarang kontrol ke puskesmas karena alasan jauh atau tidak ada yang mengantar. Penelitian Sabil et al., (2019) menunjukan bahwa faktor-faktor yang mendukung self-care management pada penyandang DM adalah literasi kesehatan, efikasi diri dan dukungan keluarga.

Era digital seperti sekarang sangatlah mudah untuk mengakses berbagai macam informasi, khususnya informasi mengenai kesehatan. Namun di lain pihak, sumber informasi yang beragam juga berpotensi menimbulkan mispersepsi. Literasi kesehatan merupakan kemampuan individu dalam mengakses, memahami dan menggunakan informasi serta pelayanan kesehatan untuk membuat suatu keputusan yang tepat (Alsubaie \& Salem, 2019). Pemahaman responden yang rendah dalam memahami penatalaksanaan DM disebabkan oleh literasi kesehatan yang belum optimal.

Lopez-Garrido (2020) mengatakan efikasi diri sebagai kepercayaan diri atau keyakinan seorang individu mengenai kemampuannya untuk melakukan berbagai hal. Dalam penelitian ini, keyakinan responden untuk melaksanakan self-care activity kurang sehingga mengabaikan rekomendasi diet dan olah raga. Temuan ini sesuai dengan penelitian Anindita et al., (2019) yang menunjukan bahwa penyandang DM dengan efikasi diri yang baik cenderung memiliki perilaku yang patuh dalam melaksanakan latihan fisik.

DM adalah penyakit menahun yang akan diderita seumur hidup, sehingga peran pasien dan keluarga sangat penting dalam upaya penatalaksanaan DM (Setyawati et al., 2020). Hal ini selaras dengan penelitian Hisni (2019) yang menjelaskan adanya hubungan antara dukungan keluarga dengan kepatuhan latihan fisik pada pasien DM tipe 2. Demikian juga dengan penelitian Bangun et al., (2020) yang menunjukan bahwa dukungan keluarga merupakan faktor penting dalam kepatuhan pasien DM terhadap program diet. Dalam penelitian ini, keengganan responden untuk berolahraga dan menjalankan diet disebabkan karena dukungan keluarga yang tidak adekuat.

\section{Self-Care Activity Setelah Terapi Psikoedukasi}

Tabel 2 menunjukkan bahwa nilai rerata self-care activity setelah terapi edukasi adalah 23,00 yang bermakna bahwa responden memiliki self-care activity yang baik. Prabawati \& Natalia (2020) menjelaskan bahwa 7 aspek dalam SDSCA memiliki hubungan yang erat dengan kontrol glikemik yang baik, mengurangi komplikasi dan meningkatkan kualitas hidup. Berdasarkan hal tersebut, maka self-care activity merupakan program yang harus dijalani oleh penyandang DM seumur hidupnya dengan tujuan untuk mengoptimalkan kontrol metabolik, mengoptimalkan kualitas hidup, serta mencegah komplikasi akut dan kronik

Salah satu cara untuk meningkatkan partisipasi penyandang DM agar mau melakukan self-care activity adalah dengan terapi psikoedukasi. Psikoedukasi adalah metode intervensi yang fokus mendidik partisipannya mengenai tantangan atau masalah-masalah dalam hidup. Psikoedukasi dapat dilakukan melalui sebuah pelatihan dengan metode eksplorasi, penilaian, diskusi, bermain peran dan demonstrasi (Putra \& Soetikno, 2018). Dalam penelitian ini, responden mendapatkan terapi psikoedukasi yang dilakukan dalam 5 sesi dan setiap sesinya berdurasi 30-45 menit dengan menggunakan media booklet berwarna. Materi disampaikan dengan komunikatif, menggunakan bahasa yang sederhana, mudah dipahami sesuai dengan latar belakang 
pendidikan responden melalui metode diskusi kelompok terarah. Kusaeri et al., (2020) mengatakan bahwa penggunaan metode ini dapat menggali persepsi, pendapat, sikap, motivasi, pengetahuan, masalah dan harapan perubahan berkaitan dengan masalah tertentu dalam waktu relatif singkat. Hasil penelitian juga menunjukkan bahwa saat posttest beberapa aspek sudah dijawab dengan "selalu" dan "sering". Hal ini disebabkan karena responden sudah mulai percaya diri dalam pemahaman mereka mengenai selfcare activity.

\section{Pengaruh Terapi Psikoedukasi terhadap Self-Care Activity}

Tabel 3 memperlihatkan bahwa nilai $\mathrm{P}_{\text {value }}$ adalah sebesar 0.001, maka dapat disimpulkan bahwa terapi edukasi berpengaruh terhadap self-care activity responden. Hadiansyah (2018) menjelaskan bahwa psikoedukasi merupakan suatu tindakan yang diberikan kepada individu untuk memperkuat strategi koping atau suatu cara khusus dalam mengatasi permasalahan psikologis yang dialami oleh seseorang. Oleh karena itu, penyampaian informasi yang lengkap mengenai DM dengan cara yang menarik dan berbeda dapat mengurangi kekhawatiran responden.

Perawat dalam penelitian ini memiliki peranan yang strategis untuk memberikan pemahaman yang benar serta memberdayakan keluarga agar berpartisipasi dalam selfcare activity sehingga penyulit DM yang berpotensi muncul dapat dikendalikan. Kertapati (2019) mengatakan bahwa tugas kesehatan keluarga merupakan cerminan dari kemampuan keluarga dalam mempertahankan dan meningkatkan status kesehatan keluarga. Itulah sebabnya, keluarga dari penyandang DM turut berpengaruh terhadap kesehatan seorang diabetisi, Hal ini sejalan dengan penelitian Kamalah et al., (2020) dimana psikoedukasi efektif dalam menurunkan beban keluarga pasien ulkus diabetic.

Hasil evaluasi pemahaman pretest dan posttest dalam penelitian ini, menunjukan bahwa terdapat peningkatan self-care activity pada responden. Responden mulai kembali rutin memeriksakan gula darah ke Puskesmas maupun Posbindu, berolah raga serta bertahap mengikuti rekomendasi diet DM. Hasil penelitian ini selaras dengan penelitian Huzaimah (2018) dimana pemberian modifikasi psikoedukasi berdampak pada peningkatan perilaku pengelolaan diabetes mandiri.

\section{SIMPULAN}

Terapi psikoedukasi terbukti berpengaruh terhadap self-care activity pada penderita DM. Hasil evaluasi pemahaman pretest dan posttest dalam penelitian ini menunjukan bahwa terdapat peningkatan self-care activity pada responden.

\section{SARAN}

Diharapkan perawat saat kunjungan Posbindu agar memodifikasi teknik edukasi mengenai pengelolaan dan pengendalian DM yang konvensional dengan mengimplementasikan terapi psikoedukasi. Selain itu, diharapkan juga perawat dapat memberikan motivasi kepada penyandang DM beserta keluarganya agar self-care activity-nya lebih dioptimalkan lagi sehingga dapat mencegah resiko timbulnya penyulit DM. 


\section{DAFTAR PUSTAKA}

Alsubaie, M. S., \& Salem, O. A. (2019). Nurses' Perception of Health Literacy. Annals of Medical and Health Sciences Research, 9(6), 716-722. https://www.amhsr.org/articles/nurses-perception-of-health-literacy.pdf

Anindita, M. W., Diani, N., \& Hafifah, I. (2019). Hubungan Efikasi Diri dengan Kepatuhan Melakukan Latihan Fisik pada Pasien Diabetes Mellitus Tipe 2. Nusantara Medical Science Journal, 4(1), 19-24. https://doi.org/10.20956/nmsj.v4i1.5956

Bangun, A. V., Jatnika, G., Herlina, H. (2020). Hubungan antara Dukungan Keluarga dengan Kepatuhan Diet pada Penderita Diabetes Mellitus Tipe 2. Jurnal Ilmu Keperawatan Medikal Bedah, 3(1), 1-76. http://dx.doi.org/10.32584/jikmb.v3i1

Hadiansyah, T. (2018). Efektivitas Intervensi Psikoedukasi terhadap Tingkat Kecemasan Keluarga Dalam Merawat Pasien Skizofrenia. Jurnal Skolastik Keperawatan, 4(2), 49-61. https://jurnal.unai.edu/index.php/jsk/article/view

Hidayah, M. (2019). Hubungan Perilaku Self-Management Dengan Kadar Gula Darah pada Pasien Diabetes Mellitus Tipe 2 di Wilayah Kerja Puskesmas Pucang Sewu, Surabaya. Amerta Nutrion, $3(3), \quad$ 176-182. http://dx.doi.org/10.20473/amnt.v3i3.2019.176-182

Hisni, D. (2019). Hubungan Dukungan Keluarga dengan Kepatuhan Latihan Fisik pada Pasien Diabetes Mellitus Tipe 2 di Puskesmas Pancoran Jakarta. Jurnal Ilmu Keperawatan dan Kebidanan Nasional, 1(1), 1-10. http://journal.unas.ac.id/health/article/view/491

Huzaimah, N. (2018). Model Psikoedukasi untuk Meningkatkan Pemahaman dan Efikasi Diri Penderita Diabetes Mellitus Tipe 2. Jurnal Kesehatan Wiraraja Medika, 8(1), 19-26. https://doi.org/10.24929/fik.v8i1.506

International Diabetes Federation. (2019). IDF Diabetes Atlas 9th Edition. https://www.diabetesatlas.org/en/sections/demographic-and-geographicoutline.html

Kamalah, A. D., Ahsan, A., \& Kristianto, H. (2020). Efektivitas Psikoedukasi Keluarga dalam Menurunkan Beban Keluarga pada Keluarga Pasien Ulkus Diabetes Melitus. Jurnal Ilmu Keperawatan Jiwa, 3(1), 9-16. https://doi.org/10.32584/jikj.v3i1.339

Kementerian Kesehatan Republik Indonesia. (2018). Hasil Utama Riset Kesehatan Dasar.

https://kesmas.kemkes.go.id/assets/upload/dir_519d41d8cd98f00/files/Hasilriskesdas-2018_1274.pdf

Kertapati, Y. (2019). Tugas Kesehatan Keluarga dan Tingkat Kemandirian Keluarga di Wilayah Pesisir Kota Surabaya. Jurnal Ilmiah Keperawatan, 14(1), 1-10. https://doi.org/10.30643/jiksht.v14i1.47

Kusaeri, S. K. M., Haiya, N. N., \& Ardian, I. (2020). Promosi Kesehatan dengan Metode Focus Group Discussion Dapat Mempengaruhi Pengetahuan tentang Diabetes Mellitus. Bima Nursing Jurnal, 1(2), 113-118. http://jkp.poltekkesmataram.ac.id/index.php/bnj/article/view/490

Lopez-Garrido, $\quad$ G. $\quad$ (2020). Self-Efficacy Theory. https://www.simplypsychology.org/self-efficacy.html

Massi, G., \& Kallo, V. (2018). Efektifitas Pemberian Edukasi dengan Metode Video dan Focus Group Discussion (FGD) terhadap Tingkat Pengetahuan Pasien DM 
Tipe 2 di Klinik Diabetes Kimia Farma Husada Manado. Jurnal Keperawatan, 6(1), 1-6. https://ejournal.unsrat.ac.id/index.php/jkp/article/view/25182

Perkumpulan Endokrinologi Indonesia (PERKENI). (2019). Pedoman Pengelolaan dan Pencegahan Diabetes Melitus Tipe 2 Dewasa di Indonesia. https://pbperkeni.or.id/wp-content/uploads/2020/07/Pedoman-Pengelolaan-DMTipe-2-Dewasa-di-Indonesia-eBook-PDF-1.pdf

Prabawati, D., \& Natalia, L. (2020). The Effectiveness of Self-Care Model on Diabetes Self-Management Behaviour. Indonesian Nursing Journal of Education and Clinic (INJEC), 5(1), 1-7. http://dx.doi.org/10.24990/injec.v5i1.277

Putra, A. S., \& Soetikno, N. (2018). Pengaruh Intervensi Psikoedukasi untuk Meningkatkan Achievement Goal pada Kelompok Siswi Underachiever. Jurnal Muara Ilmu Sosial, Humaniora, dan Seni, 2(1), 254-261. https://doi.org/10.24912/jmishumsen.v2i1.1514

Sabil, F. A., Kadar, K. S., \& Sjattar, E. L. (2019). Faktor-Faktor Pendukung Self Care Management Diabetes Mellitus Tipe 2: A Literature Review. Jurnal Keperawatan, 10(1), 48-57. https://doi.org/10.22219/jk.v10i1.6417

Setyawati, A., Ngo, T., Padila, P., \& Andri, J. (2020). Obesity and Heredity for Diabetes Mellitus among Elderly. JOSING: Journal of Nursing and Health, 1(1), 26-31. https://doi.org/https://doi.org/10.31539/josing.v1i1.1149

Sugiharto, R. N., Hsu, Y. Y., Toobert, D. J., \& Wang, S. T. (2019). The Validity and Reliability of The Summary of Diabetes Self-Care Activities Questionnaire: An Indonesian Version. Indonesian Nursing Journal of Education and Clinic (INJEC). 4(1), 25-36. https://doi.org/10.24990/injec.v4i1.229 